\title{
Lack of targets leads to underperformance in NHS services
}

\author{
Susan Mayor London
}

\begin{abstract}
Many services provided by the NHS in England and Wales have improved over the past year, but others, including mental health, sexual health, maternity, and dental services, have "been left behind," according to an annual report on the state of health care. The report, presented to parliament this week, said that a lack of targets or requirement to collect information in these areas may underlie the poorer performance.
\end{abstract}

It says that the NHS still has a long way to go to achieve a "patient-led" service. The annual report from the Healthcare Commission, an independent body that inspects and reviews various aspects of health services, focused for the first time on the experience of patients. It reviewed existing evidence on the experience of patients, including the commission's own surveys of patients.

The results showed that patients were highly satisfied with many NHS services, with more than $90 \%$ of patients who took part in the surveys rating their overall care as good, very good, or excellent. However, there were some exceptions. Only $76 \%$ of patients in mental health services were satisfied with their care.

Anna Walker, chief executive of the Healthcare Commission, said, "Clear improvements in prevention and treatment have occurred, whether there is some form of target or national service framework. There has been less progress in areas not so thoroughly covered by targets."

The report warned that less than half the people with mental health problems surveyed in 2004 said they had access to crisis care, such as an out-of-hours phone number of a mental health professional, when they needed it.

Also, only two thirds of community based crisis resolution teams operated around the clock, the report found, even though the purpose of these services is to prevent the need to hospitalise adults with acute psychiatric crises by providing 24 hour community based treatment.

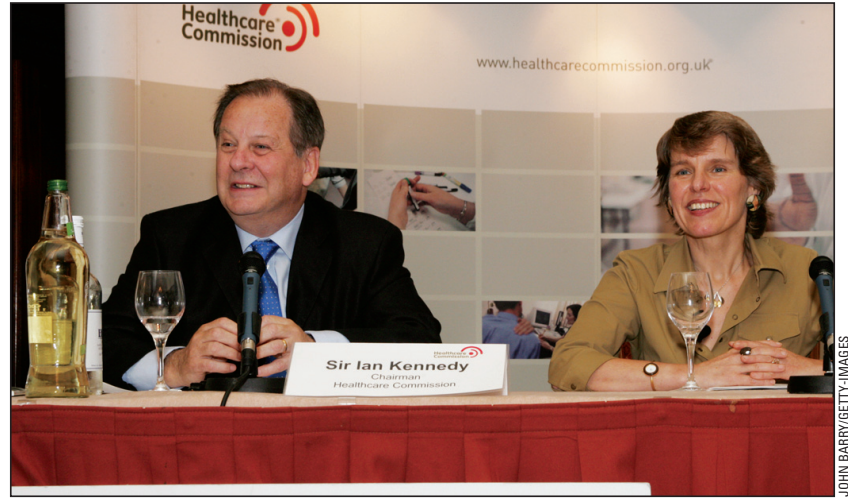

Anna Walker, chief executive of the Healthcare Commission (pictured with chairman Professor Ian Kennedy) said there had been less progress in areas not covered by targets

The report found long waiting times for sexual health services, with $28 \%$ of people who needed to be seen urgently having to wait more than 48 hours and $29 \%$ of people who had symptoms of sexual infection waiting more than two weeks.

The report highlighted major problems in some maternity services. It warned that

\section{Blind eye to complaints allowed psychiatrists to abuse patients}

\section{Clare Dyer legal correspondent, BMJ}

An NHS culture of turning a blind eye allowed two psychiatrists to get away with sexually abusing scores of vulnerable women patients through the 1970s and 1980s. This was the conclusion this week of the report of an independent inquiry commissioned by the Department of Health.

Concerns and complaints about William Kerr and Michael Haslam were never acted on by the NHS, and they were allowed to retire in 1988. They were also allowed to remove themselves voluntarily from the medical register, avoiding disciplinary action by the General Medical Council.

Complaints were ignored, consultants were seen as "all powerful," and colleagues were reluctant to raise concerns about fellow professionals, concluded the inquiry's panel, which was chaired by Nigel Pleming QC.

Haslam, 71, was jailed in 2003 after he was convicted of four counts of indecently assaulting patients. A conviction for rape was later quashed by the Court of Appeal.

Kerr, 77, who has a brain wasting disease, was convicted in his absence of one count of indecent assault in 2000. He was given an absolute discharge but placed on the sex offenders' register.

"Patient complainants largely got nowhere, professional complainants often fared worse, attracting blame, criticism and a degree of professional ostracism that deterred others from following their lead," the report said.

Professionals were reluctant to take any action against consultants out of "a misguided sense of loyalty and fear of confrontation," and administrators devised mechanisms to protect themselves rather than patients. three independent investigations into maternity services over the past two years had shown a range of problems, including inadequate support for women who do not speak English, overcrowding, and poor standards of cleanliness

State of Healthcare 2005 is available at www.healthcarecommission.org.uk
The inquiry heard evidence that Kerr, who worked at Clifton Hospital in York from 1965 until his retirement in 1988 , was guilty of "sexualized behaviour" with at least 67 women. Some had come forward only during the inquiry, but 38 claimed to have made disclosures at the time, not one of which was investigated.

Haslam, who was appointed a consultant at Clifton Hospital in 1970 , gave rise to at least 10 complaints of sexual advances, but it was only after a complaint of sexual assault that he was "allowed, perhaps even encouraged," to retire from the NHS. He continued to work in private practice.

The Kerr/Haslam Report is available at www.dh.gov.uk 